Martin Aitken*

\title{
Generic assumptions in utterance interpretation: the case of indirect instructions ${ }^{\text {a }}$
}

\begin{abstract}
This article addresses the role played by genre in the way in which language users interpret 'indirect' directive utterances in the special discourse context of technical instructions. In linguistics, issues of genre have most often been approached from socially oriented frameworks such as systemic functional linguistics and the ethnomethodology of the Swales-Bhatia school. The present article instead adopts the cognitive framework of relevance theory to account for a process of comprehension founded on two modularised cognitive processes, viz. decoding of semantic content and relevance-driven inferential manipulation of resulting representations to which generic assumptions about the discourse provide significant contextual input.
\end{abstract}

\section{Concerns}

My primary concern with the present article is to outline how genreactivated elements of context contribute in a principled manner to the representation of directive utterance meaning in technical instructions. I refer to such elements generally as situational features of the discourse, contrasting with textual features and conflating, or cross-cutting, Hallidayean 'context of situation' and Martinean 'context of culture'.

The kinds of data with which I am concerned are what have most often been referred to in the literature since Searle (1975) as 'indirect speech acts', i.e. those utterances whose interpretations in some way

\footnotetext{
An earlier version of this article was presented as a paper at the International Conference on Research and Practice in Professional Discourse, City University of Hong Kong, November 2000.

* Martin Aitken

Copenhagen Business School

Department of English

Dalgas Have 15

DK-2000 Frederiksberg
}

Hermes, Journal of Linguistics no. 28-2002 
would seem to be at odds with their so-called 'literal' meanings. ${ }^{1}$ However, my approach to such examples departs from that of Searlean speechact theory in a number of significant ways, a fact which I assume will become evident, though I shall not be specifically concerned with that issue here.

Although the general framework of systemic functional linguistics (e.g. Halliday 1994, Martin 1992) and the more ethnographically inclined approach of the Swales-Bhatia school (Swales 1990, Bhatia 1993) have provided two coherent theoretical platforms for much genre-oriented work in the field of specialised discourse, my point of entry into considerations of genre is informed by a quite different framework with a quite different agenda, viz. that of relevance theory (Sperber \& Wilson 1986/1995).

Relevance theory is a cognitive theory of communication which is concerned with how language users interpret linguistic stimuli. I do not intend here specifically to confront that framework with, say, systemic functional linguistics (for insightful discussion of these two approaches from a relevance-theoretical perspective, including a critique of Thibault's (1999) extreme anti-cognitive view, see Unger 2001). Neither do I seek in what follows to characterise the genre of technical instructions by way of any more or less embracing analysis of, say, register or schematic structure. Rather, I shall be concerned with how the receiver's assumption that a text constitutes a specific genre-instantiation activates a set of significant assumptions about the nature of the discourse and the originator's macro-level intentions. These assumptions, as will be outlined, are then utilised by the receiver at the sub-textual micro-level together with semantic information encoded in the utterance in a process of dynamic, inferential meaning construction. Bearing this in mind, however, it will be useful for purposes of broad orientation, where appropriate, to point to some areas of potential conflict between a relevancebased cognitive framework and more socially oriented approaches of

\footnotetext{
1 There is no direct correspondence between sentence and illocution, so the formfunction relationship is always either more or less indirect. However, because of its wellentrenched nature in the literature, and since imperative sentence-type at the semantic level would seem to be more well-suited to directive functions than the declarative (making the latter more indirect than the former), I choose to retain the term as a convenient label for the kinds of data discussed here.
} 
the kind more traditionally employed in discussions in which the concept of genre is taken to be significant.

\section{The data}

The following examples are culled from a small corpus of British English instructions for use. Though illustrative of the kinds of data for which I seek to account, the set provided here is by no means exhaustive of the range of possible types:

(1) The tape marks the end that goes towards the signal source.

(2) A qualified technician can recalibrate the Graseby 3100 to accept any one of the following syringe makes: [...].

(3) The patchcord fibre is connected to the source emitter and to the instrument and a dBm measurement made.

(4) The pump may be placed on a flat stable surface or mounted on a vertical pole or rail using a clamp.

(5) Is the air inlet obstructed in any way?

For present purposes I shall concentrate on the first of these examples only, electing thereby to pursue (primarily in sections 7 and 8) more detailed exposition at the expense of constraining descriptive reach. However, expository strategies notwithstanding, it is my claim that the framework employed here provides, not merely a strong descriptive tool, but also a very powerful explanatory apparatus with regard to accounting for how language users interpret the kinds of utterances as are exemplified by (1) - (5) above, as well as others like them (cf. Aitken 2000).

As may be noted, (1) encompasses none of the traditional formal markers of modality in English (cf. Perkins 1983); neither does its explicit content include specification of any prospective event involving the receiver as agent. For convenience, the immediate co-text of (1) is provided below in ( $\left.1^{\prime}\right)$ (emphasis added), although the role of co-text in utterance interpretation will not be confronted here. Co-text clearly yields assumptions that provide incremental input to interpretation. However, those assumptions may be genuinely indispensable to the extent that they comprise information which cannot otherwise be inferred and without which a relevant hypothesis as to the originator's informative intention cannot be constructed, or they may merely specify information which is necessary for the construction of such an hypothesis but which 
112

nevertheless might be inferred without necessarily having been textualised. Here, I will assume that the latter is the case.

(1') Cables and connections

[...] One end of each cable is marked with a strip of tape to establish

its direction. The tape marks the end that goes towards the signal source.

\section{The problem}

I claim that (1) - (5) are interpreted in such a way as to allow the receiver to fully specify an assumption schema of the type rendered in (6):

(6) The originator is instructing me to [p]

where $\mathrm{p}$ is a dynamic agent-event (i.e. an event requiring the wilful intervention of a human agent in the way of the world, cf. Durst-Andersen 1992, Klinge 1993) with the receiver R occupying the agent role, minimally:

(7) $\quad R$ ensure $x$

where $\mathrm{x}$ is any state-of-affairs that may hold in the world.

I take 'instructing' in this context to consist in the provision of information relevant to the establishment by means of a technical device of some state-of-affairs desired by the receiver. In classificatory terms, information is relevant to an individual to the extent that it provides new assumptions, or strengthens, cancels or otherwise modifies existing assumptions held by that individual, i.e. to the extent that it yields 'positive cognitive effect' in one or more available context (Sperber \& Wilson 1995: 265). In more specific comparative terms, relevance is a balanced relation between effort and effect, whereby an assumption yielded by processing a stimulus is deemed optimally relevant when the effort involved in processing is small and the effect gained is large (ibid.).

In the case of (1), the utterance as part of a set of instructions for use is taken to provide information relevant to the receiver using a certain brand of stereophonic equipment in order to establish a state-of-affairs whose primary characteristics conceivably involve him sitting and enjoying his favourite CD release. More specifically, the relevant interpretation of (1) will involve the receiver representing the informative intention of the originator in terms of an intention to furnish him with 
the information that the agent-event rendered in (8) is relevant in a particular way to the receiver's establishing his desired state-of-affairs:

(8) R ensure [x GO TOWARDS y]

Given its specific context, (1) will be construed in directive terms in much the same way as interpretations of instructional imperatives, i.e. as an instance of the originator imposing or (in this case) proposing some course of action or pattern of behaviour and indicating that it should be carried out (Lyons 1977: 745-6). Similar interpretations can be posited for the examples (2) - (5).

However, it is clear that the underlying encoded content of (1) severely underdetermines this kind of functional interpretation. On encountering (1), the linguistic input module will automatically decode the utterance into its underlying logical form, whereby the receiver will form a mental representation of the encoded semantic content, something like that simplified in (9): ${ }^{2}$

(9) DEC [ACTIVE $\left[\operatorname{mark}\left(x_{\text {[SPECIFIED] }}, y_{\text {[SPECIFIER }]}\right]\right]$

Since encoded content in this way underdetermines, not only functional, but also propositional meaning (the kind of schematic representation rendered by (9) cannot be assigned any truth-value and is therefore clearly non-propositional), some kind of principled explanation of how the receiver gets from (1) to (8) is clearly required in order to account fully for the recovery of utterance meaning. Relevance theory, briefly outlined below, provides just the kind of framework we need, holding that utterance meaning is dependent not only on decoding, but also, and significantly, on inferential processing involving decoded semantic content and activated contextual assumptions. Context, as will presently be made evident, is here understood as a psychological construct, a set of assumptions activated in the communicative situation and used as premises in interpreting an utterance (Sperber \& Wilson 1986/1995: 15).

The idea that meaning construction in human verbal communication generally is dependent on, not one, but two specific cognitive processes is particularly worth noting at this juncture since it would seem to contrast sharply with traditional linguistic approaches to genre such as that taken

2 Sentential semantic structure as represented in (9) is briefly outlined in section 7 below. 


\section{4}

by systemic functionalism. Systemically inclined scholars have paid little, if any, direct attention to the cognitive basis of communication, despite more or less explicit claims to holism. Instead, systemic functional linguistics, with its defining emphasis on language as semiotic, would seem merely to proceed from the assumption that human verbal communication essentially is a matter of the simple decoding of messages encoded in (socially negotiated) linguistic signals. In other words, an implicit reliance on what Sperber \& Wilson (1986/1995) refer to as the code model of communication. This clearly leaves little room for pragmatics, a fact that has been lamented even from within systemic ranks. For example, Butler (1988) has sought incorporation of a pragmatic component in the systemic framework by pointing to a number of problem areas for a non-pragmatic systemic theory, among them notably 'indirect speech acts'. Here, Halliday's (1984) stratificational model of dialogue is criticised for its failure to provide an indication of the principles that might be involved in choosing and interpreting 'indirect' forms. Elsewhere, Butler has challenged the systemic view of the communicative function of utterances, referring again to Halliday's (1984) model, which he construes as suggesting "an approach in which communicative function is incorporated within semantics" (Butler 1987: 213).

The code model of communication provides a satisfactory account of the recovery of semantic meaning insofar as the grammar of a language is a code arbitrarily pairing phonetic (and graphemic) signals with semantic representations of sentences. However, since semantics generally underdetermines utterance meaning (and, more controversially, propositional meaning), the code model alone cannot provide a full account of the interpretation process. Relevance theory provides a principled account of how semantic representations resulting from the automatised retrieval of encoded semantic information are inferentially manipulated in a pragmatic process, constrained by the principle of relevance, which integrates logical forms with readily accessible assumptions to yield hypotheses about the informative intentions of originators. Let me now render explicit the main conceptual co-ordinates in that framework, which allows us to illuminate how interpretation, rather than being a haphazard, hit-or-miss kind of affair, in fact is a highly principled cognitive process. 


\section{The principle of relevance}

The theory of relevance as proposed by Sperber \& Wilson (1986/1995) assumes that linguistic utterances are generally semantically underdetermined with respect, not only to their functional, but also to their propositional meanings. This kind of underdeterminacy means that any model of communication which favours the notion of language as code ultimately will prove inadequate as an explanation of how meaning becomes represented by language users. Code does play an important role in the way in which receivers interpret linguistic utterances, but the decoding of semantic information is only one aspect of that process, one which must generally be supplemented by pragmatic inferencing. Relevance theory proposes a model whereby decoded semantic representations are inferentially completed, developed and otherwise cognitively manipulated according to a principle of relevance (specifically the Second (or Communicative) Principle of Relevance, see Sperber \& Wilson 1995: 260ff) which follows from the general orientation of human cognition towards maximising the relevance of stimuli (the so-called First (or Cognitive) Principle of Relevance). ${ }^{3}$ Above, I drew attention to how relevance is comparatively defined in terms of a balanced relation between processing effort and cognitive effect. The communicative principle of relevance is formulated as follows (Sperber \& Wilson 1986/ 1995: 158):

(10) Principle of relevance

Every act of ostensive communication communicates a presumption of its own optimal relevance.

Note that (10) does not state that originators necessarily produce optimally relevant utterances. Rather, (10) is a descriptive claim to the effect that part of the content of a given act of ostensive communication is a presumption that that act is relevant to the receiver (ibid.: 271). This presumption is more specifically defined as in (11) below (Sperber \& Wilson 1995: 270):

\footnotetext{
3 Unless otherwise stated, the principle of relevance referred to henceforth is the Second, Communicative Principle of Relevance.
} 
(11) Presumption of optimal relevance (revised)

(a) The ostensive stimulus is relevant enough for it to be worth the addressee's effort to process it.

(b) The ostensive stimulus is the most relevant one compatible with the communicator's abilities and preferences.

As already noted in section 3 , the relevance of any given phenomenon is defined in comparative terms as a balanced relation between cognitive effects and processing effort: the more cognitive effects a phenomenon has, and the less the effort required to process it, the greater its relevance. By presupposing the optimal relevance of any act of ostensive communication, the principle of relevance directs the interpretation process in such a way as to encourage the receiver to seek an interpretation that is consistent with that principle, i.e. one which "a rational communicator might have expected to be optimally relevant to the addressee" (Sperber \& Wilson 1986/1995: 166). The first interpretation deemed consistent with the principle of relevance is taken to be the intended one: it is by definition the least costly in terms of effort, so to the extent that it also yields adequate cognitive effects and might reasonably be assumed to have been intended by the originator, it will be the only interpretation consistent with the principle of relevance.

Since the relevance of any utterance is given, the interpretive task of the receiver may be construed in terms of a cognitive search for context, i.e. the uniquely identifiable set of assumptions that will corroborate the presumption of optimal relevance by yielding an optimally relevant interpretation. One major challenge of pragmatic theory is to account for how, for any given utterance, context is activated so as to enable the receiver to form a relevant hypothesis about the originator's informative intention. In the remainder of this paper, I shall endeavour to illuminate how the concept of genre as defined below in section 5 serves to activate a relevant subset of contextual assumptions, as well as to provide, at a very general level, specification of some of their more obvious properties.

\section{The concept of genre}

Concepts are abstract psychological objects with lexical, logical and encyclopaedic entries (Sperber \& Wilson 1986/1995: 86ff). I assume that encyclopaedic entries of concepts may be cognitively arranged in frames comprising sets of related assumptions and assumption schemas 
about the concept and which may be activated by visual, verbal or other kinds of stimuli (e.g. mental) in given situations. I take 'frame' to be a general term of reference for what are variously referred to in the cognitive literature as frames, schemata and scripts. I will refer generally to assumptions, referring specifically to less fully specified assumption schemas only where appropriate.

One such frame would consist in sets of related assumptions concerning the broader kind of situation complex in which operation of a technical device is a component. We might refer to those assumptions together as an operation frame. The operation frame would conceivably include assumptions about a desired state-of-affairs (the final state or the activity component in an event involving use of a device) and the need to establish that state-of-affairs by correctly applying a specific technical device in an operating situation. It would also presumably include a conceptual slot for a text-type providing relevant information with respect to the device, including specification of appropriate behaviour with regard to its correct operation and maintenance. This latter concept may be referred to as 'instructions for use', which is thus broadly construed in terms of an abstract psychological object with an encyclopaedic entry consisting in related sets of assumptions and assumption schemas about the concept 'instructions for use'. I will refer to such assumptions and assumption schemas broadly as comprising an instructional generic frame. The frame will be activated by any token of the concept, just as in the absence of any token it may be activated by any related concept included in the more general operation frame onto which it will map.

Generally, the text-token establishes a specific discourse universe whose properties are specific and more general assumptions taken to be common to all texts associated with the conceptual text-type slot of the operation frame. I take assumptions at the more general level to be generic and organised in the instructional frame. Genre is thereby understood in terms of a concept whose encyclopaedic entry specifies assumptions about communicative events. A very similar view is taken by Unger (2001).

A psychological view of genre such as the one propounded here contrasts with more well-entrenched socially oriented conceptions such as those offered by, on the one hand, Swales (1990) and Bhatia (1993), and, on the other, Martin (1992). Swales (1990: 83ff), discussing the 


\section{8}

role of schemata and their relationships to genre, alludes to "the important role of schemata in discoursal processing and production", yet observes "that schemata alone reflect a microcosmic cognitive world dangerously adrift from communicative purpose and discoursal context" (ibid.: 91). Bhatia does seek to include a cognitive element in his 'thick description', viewing this as a necessary component in order not to undermine the importance of what he calls "tactical aspects of genre construction" (1993: 16), i.e. "the individual strategic choices made by the writer in order to execute his or her intention" (ibid.: 19). Genres are in Bhatia's view taken to display "cognitive structuring" insofar as they exhibit "cognitive regularities of organisation" reflecting mental strategies used in their construction and understanding (ibid.: 21). Cognitive structuring is textualised as a series of moves or stages constraining discourse function. Yet, in keeping with the social orientation that is also characteristic of the systemic-functional approach exemplified by Martin (1992), no account is given of the kinds of cognitive processes that might actually be at work in processing. In the view taken here, genre is by contrast essentially cognitive insofar as genres are seen as mental objects specifying sets of assumptions. If, as might reasonably be assumed, it is a central task of genre analysis to explain the role of generic structure in comprehension, then it would seem clear, given the fundamentally cognitive nature of that process, that the kind of approach suggested here provides an intrinsically more suitable point of departure.

While none of the above-mentioned scholars (Swales, Bhatia, Martin) to my knowledge has seen cause to engage directly in the specific paradigmatics at issue here, a cognitive-based approach in no way precludes the incorporation of social aspects in accounts of generic communication, even though relevance theory itself in a broader perspective has been much criticised from sociolinguistic quarters for failing to encompass a specifically social component in its model of communication. ${ }^{4}$ Talbot (1994: 3525-6), for example, refers to the framework as "asocial" and bemoans "the absence of any cultural perspective", adding that "[t]he effect is highly ethnocentric". Moreover, the conception of mind pursued

\footnotetext{
4 Thibault (1999) is the most notable recent example. More generally, Ward \& Horn (1999) presents a criticism of one relevance-based study of a phenomenon more usually treated from the angle of sociolinguistics.
} 
within the theory is "reductionist" and "precludes any sociocultural perspective on the individual's construction of knowledge" (ibid.: 3526). Clearly, these are bold claims indeed.

Sperber \& Wilson (1997) have themselves countered such general criticism, pointing to: (i) relevance theory as a necessary abstraction away from a messy and heterogeneous reality to the cognitive basis of communication, "a sound initial research strategy [rather] than some silly anti-sociological bias"; (ii) the intrinsically and non-trivially social nature of an inferential model of communication, which, in contrast to a code-based approach, actually presupposes awareness of 'self' and 'other'; and (iii) the potentially very strong implications of the cognitive and communicative principles of relevance of the cognitive and communicative principles of relevance for sociolinguistics. Moreover, a growing body of relevance-based work addressing social aspects of communication (see e.g. the works cited in Sperber \& Wilson 1997) would seem to indicate that the claims of sociologically inclined scholars as to the inherently 'asocial' nature of relevance theory are exaggerated. Curiously, Thibault's (1999) rejection of any mentalistic conception of thought, and his consequent dismissal of any cognitive-based inferential approach to communication, would seem to preclude such notions as intention and purpose, concepts which are of central importance also to sociologically inclined approaches to generic communication. As Christoph Unger (personal communication) recently has impressed upon me, it is difficult to imagine how any non-cognitive framework can get to grips with what is thereby an essentially cognitively founded genreconcept: if, as evidence suggests, such notions are central to an understanding of genre, then only a cognitively based pragmatic theory is going to be capable of dealing with them in any satisfactory way.

Incidentally, another difference worth mentioning here between relevance theory and descriptive frameworks more traditionally employed in accounts of genre is that while the latter are intrinsically concerned with text and discourse as research objects, relevance theory has hitherto placed the bulk of its emphasis on the utterance. However, as recent work attests (see Wilson 1998), there is certainly nothing inherent in the theory to preclude relevance-based accounts of higher-order text and discourse-level phenomena. 


\section{Situational discourse features}

Assumptions specified by the generic frame may be utilised by the receiver as contextual assumptions in utterance processing. What then is the more specific nature of these assumptions? Rather than providing relevant additions to, or modifications of, the individual's representation of the world (i.e. cognitive effects), these assumptions are mostly about modifying the receiver's expectations as to the relevance of the discourse. Not all assumptions activated by the genre will be relevant to interpretation of the individual utterance; those that are will be licensed by considerations of relevance, the principle of relevance directing the receiver in his search for a relevant hypothesis about the originator's informative intention, i.e. one which will provide him with adequate cognitive effect for a minimum of processing effort. The important point is that in the kind of communicative situation with which we are concerned, genrespecified contextual assumptions, rendered salient by recognition of the text-token as a type-instantiation, as well as by the wider situation in which communication takes place, will be the most readily available and thereby the ones whose activation is taken to be most likely to have been intended by the originator. Their subsequent implementation as contextual assumptions in processing thus follows naturally from the general tendency of the human cognitive mechanism towards the maximisation of relevance (cf. Sperber \& Wilson 1986/1995: 260ff) and is at the same time licensed by the second clause of the presumption of optimal relevance.

I assume that the instructional generic frame will specify assumptions concerning at least the following kinds of phenomena, just as it will yield assumptions logically deriving from combinations of those assumptions.

\subsection{Rationale and purpose}

First, it is a rather trivial observation that discourse and its conventionalisation in genre presuppose some motivating factor or rationale. In the case of instructions for use, this consists specifically in the need of the originator to provide information relevant to the instantiation of some specifiable state-of-affairs which is desired by the receiver and which may be established by means of the product to which such information relates. In our example, that state-of-affairs would, as already noted, 
conceivably involve the receiver relaxing and enjoying his favourite $\mathrm{CD}$ release, although in some cases the desired state-of-affairs may be more obviously complex. Indeed, it is this desire on the part of the receiver that ultimately provides the foundation for a complex of related needs and consequent actions on both sides of the communicative fence. Thus, the desire for some state-of-affairs to hold in the world may give rise to an attendant need for some technical device by which that state-of-affairs may be instantiated, just as that need in turn may motivate production of such a device. Further, unfamiliarity with technical devices spawns a cognitive need for provision of relevant information, the fulfilment of which motivates textualisation and subsequent conventionalisation, just as it motivates the engagement of the receiver as an active participant in the discourse. While textualisation is motivated by a need for relevant information, the communicative purpose of the text is to fulfil that need. ${ }^{5}$

What we have then initially is a complex of interrelated desires and needs issuing from the single desire of the receiver for a given state-ofaffairs - let's call it D here for convenience - to hold in the world. The complex yields (i) a rationale for textualisation and conventionalisation in the form of a need on the part of the originator to provide information relevant to instantiation of $\mathrm{D}$ by means of a given technical device, and (ii) a communicative purpose consisting in the provision of such information.

\subsection{Discourse participants}

The interrelated desires and needs of originators and receivers comprise a set of mutual interests, just one property of the discourse participants. Minimally, texts require an originator as constitutive agent. However, in order for us to be able to talk about discourse in any meaningful way, texts also require receivers. I refer to originators and receivers of technical instructional texts as participants in the discourse. Some of their significant properties are as follows.

\footnotetext{
5 The notion of communicative purpose, central to much genre theory, may be somewhat complex and rather elusive (see Askehave \& Swales 2001). Nevertheless, I venture to suggest that the communicative purpose generically uniting instantiations of instructional discourse is as stated.
} 


\section{2}

One significant assumption about instructional discourse specifies the originator's knowledge of the device as authoritative. Receivers of technical instructions, on the other hand, are assumed to be relatively naïve as regards the device, its properties and its correct operation and maintenance, though they may of course be more knowledgeable than the originator about the wider discourse domain of, say, electrical engineering. Incidentally, we might distinguish here between the originator as technical writer and the originator in a wider sense as the sum of domain knowledge embodied by the manufacturing company. I assume the scope of special knowledge to be greater in the latter case than in the former.

Relatively inferior device-related knowledge compared to originators is thus one characteristic of receivers of instructional texts. Another is the cognitive goal that all receivers of such texts are assumed to share, viz. the assimilation of information relevant to instantiating a desired state-of-affairs by means of device-operation. While this does not provide any compelling reason to believe that the device-operating situation will ever be instantiated, it will nevertheless be an assumption of the originator that the instantiation of that operating situation (what might be referred to as 'functional uptake') does indeed form part of the receiver's set of goals, not least because it is taken to be a precondition of the fulfilment of the receiver's discourse-constitutive need to establish a certain stateof-affairs in the world.

Although originators in principle may be indifferent as to whether functional uptake occurs, they are hardly indifferent as to the outcome of behavioural specifications in the text in the event that uptake does occur. For that eventuality, instructions ought at least to be adequate, and this will be a genuine concern of conscientious originators. While the generic frame will specify the assumption that information provided by the text will indeed be adequate, or relevant, this assumption is actually one which is licensed directly by the principle of relevance insofar as the receiver's presumption of optimal relevance involves the presumption that the originator has made his stimulus as relevant as possible according to his aims in the discourse. This does not mean that generic assumptions are rendered superfluous by the principle of relevance. While the principle of relevance provides the assumption that the stimulus is relevant, what generic assumptions do is modify the receiver's expectations about that 
relevance, helping to specify in what way the stimulus is relevant by providing just the contextual co-ordinates to yield a relevant hypothesis about the originator's informative intention.

As briefly outlined above, participants in instructional discourse of the kind dealt with here are in part characterised by a range of mutual interests. Generic assumptions about those interests provide one potential source of contextual input to processing. An important goal of manufacturers has to do with meeting the needs of consumers; this is quite simply part of the rationale of business in that fulfilling consumer needs is taken to be conditional of the accumulation of capital which all business ventures in one way or another seek to pursue. Manufacturers are of course keenly aware of competitive parameters and the conscientious among them will seek to maximise the relevance of their texts in pursuit of their goals. Significantly, one subset of those goals consists in the fulfilment of the goals of the consumer. Receiver-goals consist primarily in the realisation of desired states-of-affairs by means of device-operating tasks, whereas originator-goals consist in the fulfilment of receiver-goals as a means of achieving higher-order business-related goals. The realisation of states-of-affairs considered desirable by receivers thus becomes a goal, not only of receivers, but also of originators. One important condition of achieving this goal is the provision of relevant information in respect of those device-operating tasks which are taken to be constitutive of desired states-of-affairs. Thus, while the principle of relevance licenses the receiver's assumption of the optimal relevance of the stimulus, the rationale of business operates on the originator, encouraging him to actually provide relevant information. Whether he does or not may of course be quite another matter. Nonetheless, the principle of relevance ensures that relevance is assumed by virtue of the ostensive nature of the stimulus, and generic assumptions concerning the mutual interests of commercial parties will serve to provide further evidence for that relevance, as well as to constrain processing as input in deductive inferencing. I shall presently try to outline how this works.

\subsection{Mutual manifestness}

The situational assumptions deriving from such features as are outlined here may be taken to be manifest, not only to the receiver, but also to the originator. In relevance theory, an assumption is manifest to an individual 
124

at a given time to the extent that it may be mentally represented and held as true or probably true. The set of manifest assumptions of an individual is referred to as a cognitive environment, "analogous, at a conceptual level, to notions of visual or acoustic environment at a perceptual level" (Sperber \& Wilson 1987: 699). What determines the manifestness of an assumption in a cognitive environment is the extent to which the environment provides evidence for its adoption (Sperber \& Wilson 1986/1995: 39). An assumption may for instance be manifest by virtue of it being logically derivable from or otherwise consistent with the cognitive environment, or it may be evidenced by the physical environment.

Given the culturally 'epidemic' nature of genres as shared cultural knowledge (cf. Sperber 1996), situational assumptions of the kind outlined above may be assumed to be manifest to both the receiver and the originator as participants in conventionalised discourse. For the originator, the manifest nature of those assumptions is a simple prerequisite of textualisation: their absence from the cognitive environment would preclude the communicative event. For the receiver, they are activated at the general level by his engagement as a party to a commercial exchange motivated by his need to instantiate a state-of-affairs, and more specifically by the originator's ostensive communication of the fact that the discourse is an instantiation of a specific genre, viz. instructions for use.

The mutual manifestness of situational assumptions will moreover itself be manifest to both originator and receiver, just as it will be manifest to both participants that this is mutually manifest. Again, this derives from the culturally epidemic nature of genre, as well as from the specifically mutual nature of the interests of the participants as specified by the assumptions themselves. That is, the set of assumptions specified by the generic frame constitutes a mutual cognitive environment in which every manifest assumption is mutually manifest to the discourse participants (Sperber \& Wilson 1986/1995: 41-42). The mutual manifestness of situational assumptions means that the originator has reasonable confidence that the receiver has access to the requisite contextual input, though in contrast to a notion of mutual knowledge it does not entail that communication proceeds according to an algorithmic heuristic involving a fixed, rather than actively constructed context (Sperber \& Wilson 1986/1995: 41-46). Assuming their mutual manifestness, all the 
receiver has to do is access those assumptions and utilise them as contextual co-ordinates in relevance-driven processing.

In section 5 above I noted Sperber \& Wilson's (1997) suggestion of the potentially strong implications of relevance theory at the level of sociolinguistics. Those implications derive from the claim that human beings strive to maximise the relevance of the stimuli to which they are exposed and to which they accord attention (the so-called First, or Cognitive, Principle of Relevance). This means that individuals to a significant extent are able, not only to predict the mental activity of others, but also to influence that activity by manipulating each other's expectations of relevance. The most direct way of doing this is by providing an ostensively communicated stimulus such as a linguistic utterance, the very act of which itself creates very specific expectations of relevance (this is the Second, or Communicative Principle of Relevance, as given in (10) above). Indeed, this is "the most important means by which the psychological tendency to maximise relevance is socially exploited" (Sperber \& Wilson 1997).

By ostensively communicating that the discourse is an instantiation of a specific genre, the originator, by virtue of the culturally epidemic nature of genres as cultural knowledge, can be reasonably assured: (i) that the receiver will access an instructional frame comprising the kinds of mutually manifest general assumptions as have been outlined above; and (ii) that those assumptions, by virtue of considerations of relevance, will be activated as contextual input to processing. The principle of relevance is thus actively exploited in order to establish a discourse universe whose participants are defined inter alia according to social parameters concerning knowledge and their specific roles in the commercial exchange of goods and services. This clearly is a principled way of bringing sociocultural aspects into the description.

Having suggested a relation between situational features of instructional discourse and assumptions specified by an instructional generic frame, let me now try to sketch out how, in processing (1), the receiver employs situational representations as significant contextual input in an inferential process of comprehension constrained by the principle of relevance. 
126

\section{From linguistic stimulus to the proposition expressed}

I have already rendered the logical form of (1) in terms of (9) above. This inevitably rather crude paraphrase, which for simplicity ignores the contributions made by the categories of tense (non-past) and aspect (non-progressive), represents the decoded semantic content of (1) as it is represented by the receiver. Like Blakemore (1992), I view sentential semantics as comprising a relation between conceptual and procedural content, the latter providing receivers with instructions as to how to process the former. Thus, (9) comprises conceptual content organised as a relation between a predicate and its arguments in what I call a 'propositional schema' (Aitken 2000). Procedural information is supplied by a 'propositional modifier' (ibid.) category of voice (here: ACTIVE), and by the sentence-type, in this instance declarative (DEC). Note that the lexical entry for the predicate supplies general semantic roles (Bache \& Davidsen-Nielsen 1997) to the logical form, these being enriched by subsequent processing involving the application of the procedural mechanics of the category of voice (Aitken 2000: 229-236). ${ }^{6}$ Choices of logical forms arising in cases of ambiguity (for example between a dynamic and a stative lexical entry for the predicate, each supplying its own set of appropriate general roles to arguments) are assumed to be resolved by a process of inferentially evaluated decoding such as that outlined by Sperber \& Wilson (1986/1995: 186-7).

Logical forms are abstract non-propositional conceptual representations which provide input to central inferential processing. In order for receivers to be able to form relevant hypotheses about the informative intentions of originators, logical forms have to be completed into fully propositional representations capable of being true or false. The first step in this process comprises the application of three interpretive sub-

\footnotetext{
6 Voice does the job of keying predicate arguments and their attendant general roles to syntactic functions of the sentence. While the lexicon will stipulate that a given predicate has a given number of arguments (textualised or untextualised), each with its own general semantic role (e.g. DOER/DONE-TO in the case of dynamic representations, SPECIFIED/ SPECIFIER in the case of non-dynamic representations, cf. Bache \& Davidsen-Nielsen 1997), voice instructs the receiver to represent those arguments as being realised by e.g. grammatical subjects and objects. Once it is established that e.g. a general DOER role is realised by a subject string such as The Prince of Denmark, inference will enrich that role into a more specific representation such as a controlling AGENT (as opposed to, say, a non-controlling FORCE).
} 
tasks directed by considerations of relevance, viz. reference assignment, disambiguation and enrichment (another operation is the application of procedural content provided by propositional modifiers, cf. Aitken 2000).

I have already mentioned disambiguation and am assuming that inferentially evaluated decoding selects (9) as the appropriate logical form. Further, I assume that (1) renders enrichment superfluous (for details, see Carston 1988). As regards reference assignment, considerations of relevance encourage the receiver to look in the most likely context for referents of arguments, since this will require least effort for a potentially positive effect. The most likely context in which to locate the referents of the subject and object noun phrases in (1) is the immediate discourse-external situation to which the instructional text is intended to relate. That this is so results at least in part from the general situational assumption, provided by the generic frame, to the effect that the macrolevel referent of instructional discourse is the device which the text accompanies.

Thus, the presumption of optimal relevance in (11) states that it is a presumption of the receiver that the originator has made his stimulus as relevant as possible given his abilities and preferences, i.e. his cognitive goals in the discourse. More specifically, situational assumptions will specify one of those goals as concerning the provision of relevant information with regard to the receiver's establishing a desired state-of-affairs by means of a device specified by the accompanying text which has the device as its object. In other words, the situational assumption provided by the generic frame specifies, or fleshes out, those preferences of the originator which the principle of relevance at the more general level points to as constraining the relevance of the stimulus. This provides a mental context for reference assignment which in the communicative situation may be matched by a specific discourse-external state-of-affairs in which the technical device is one participant.

Let's assume now that the receiver has inferentially completed the schematic logical form (9) specified by the encoded semantics of the utterance. The resulting representation is a fully truth-evaluable propositional form (PF) - a so-called explicature of the utterance, i.e. "a combination of linguistically encoded and contextually inferred conceptual features" (Sperber \& Wilson 1986/1995: 182) - such as that paraphrased by (12) below: 
128

(12) ${ }^{\mathrm{PF}}$ The tape marks the end that goes towards the signal source

However, since (12) falls short of the kind of representation given in (8), which I am claiming construes the relevant interpretation of (1), the interpretive task of the receiver is clearly by no means complete. Language users are not merely in the business of constructing and storing propositions; rather we entertain those propositions in various ways as communicating individuals. So although we may assign a truth-value to (12), doing so would not in any way exhaust the communicative import of the utterance by means of which it was conveyed.

\section{Explicatures and implicatures}

Propositional forms are inferentially developed by being embedded in assumption schemas provided by the procedural category of sentencetype. However, just as the logical forms of utterances underdetermine propositional forms, so sentence-type underdetermines the propositional attitude of the originator. Embedding (12) in the appropriate assumption schema for declarative sentence-type results in the following representation which construes the procedural semantics of DEC as instructing the receiver to process the propositional form as a description of an actual state-of-affairs (Sperber \& Wilson 1986/1995: 243ff):

\section{(13) The originator is saying that [The tape marks the end that goes towards the signal source]}

The task of the receiver is then to ascertain in what way the originator intends (13) - in relevance-theoretical terms a so-called higher-level explicature (Sperber \& Wilson 1986/1995: 246ff) - to be relevant. This is done by processing (13) together with, inter alia, manifest situational assumptions specified by the activated generic frame.

Now, one such assumption, (15), I take to be the result of logical operations between assumptions concerning the kinds of situational features outlined in section 6 and related assumptions about the communicative properties of utterances in instructional discourse. Significantly, (15) will inferentially combine with (14), which construes the presumption of optimal relevance that is part and parcel of the communicated content of any ostensive stimulus, in order to deductively yield (16):

(14) The originator is being optimally relevant 
(15) Being optimally relevant in instructional contexts involves communicating the PFs of declarative utterances as explicatures

(16) The originator is communicating that [The tape marks the end ...]

The deduction thereby provides the receiver with evidence for the assumption that the receiver wishes to communicate the propositional form as an explicature of the utterance, i.e. that he is actually asserting (12). However, he has not yet reached a relevant interpretation, one that balances processing effort with cognitive effect. Let us now consider how such an interpretation might be reached on the basis of (16).

The generic frame yields a general assumption schema (17) about the relevance of utterances contained in instructional texts $(\mathrm{C}$ is the context, $\mathrm{D}$ the desired state-of-affairs):

(17) $U$ is relevant in C [U contributes positively to D]

The schema is specified in the context of (1) as a full-fledged assumption (21) about the relevance of the propositional form, recovered by inferentially combining (18) - (20), where (19) is a situational assumption about the discourse supplied by the generic frame:

(18) The originator is being optimally relevant

(19) Being optimally relevant entails providing $\mathrm{R}$ with information that contributes positively to the desired state-of-affairs

(20) The utterance communicates that [The tape marks the end ...]

(21) [The tape marks the end ...] is relevant in a context in which it contributes positively to $\mathrm{R}$ enjoying his favourite $\mathrm{CD}$ release

The task of the receiver is now to further specify the relevant processing context by establishing in what way the propositional form contributes positively to his desired state-of-affairs, i.e. how it achieves its relevance. At every stage along the way, considerations of relevance entail that he choose the path of least effort and potentially large effect.

Now, although the propositional form of the utterance clearly describes a stative situation, it is equally evident that the post-head modifying clause of the object noun phrase describes a dynamic state-of-affairs, represented by the receiver in terms of an event comprising qualitatively discrete initial and final states connected by an activity (cf. DurstAndersen 1992). Ontological background knowledge of the typology of situations informs the receiver that activity requires initiation either by 
some non-controlling force or some controlling agent. At the same time, domain and other background knowledge specifies that the end marked by tape going towards the signal source is a desirable activity to the extent that it is a prerequisite of the cable actually being connected to the signal source, which in turn is a condition of the receiver achieving the desired state-of-affairs.

These kinds of assumptions might combine as premises along the lines of (22) and (23), a further premise (24) deriving from a general situational assumption supplied by the generic frame and more fully specified by the particular context of the utterance. The deduction yields (25) as its conclusion:

(22) D is desirable to $\mathrm{R}$

(23) The event-representation 'force or agent produce activity [the end marked by tape go towards the signal source]' is relevant to R achieving D

(24) R achieving $\mathrm{D}$ is contingent upon relevant event-representations being instantiated in the discourse-external world

(25) The instantiated event is desirable to $\mathrm{R}$ with regard to him enjoying his favourite $\mathrm{CD}$ release

However, (25) still does not exhaust the relevance of the utterance. In order for the gained effect to be cognitively adequate, the receiver has to supply further assumptions provided by the specific context and only more generally by the generic frame. Thus, (26), while specifying a situational assumption to the effect that events relevant to $\mathrm{D}$ will be events produced by wilful agents rather than non-controlling forces, can at this stage be constructed purely on the basis of the specific context of utterance using more general background assumptions. (27), on the other hand, derives from a situational assumption specifying that the intended receiver of the text is himself responsible for ensuring the instantiation of events presented as relevant to D. (25), then, combines inferentially with (26) and (27) to deductively yield (28) as an implicature of the utterance:

(26) The event requires the intervention of an agent

(27) $\mathrm{R}$ is the agent

(28) The event ' $\mathrm{R}$ ensure [agent produce activity [the end marked by tape go towards the signal source]]' is desirable to $\mathrm{R}$ with regard to him enjoying his favourite $\mathrm{CD}$ release 
Since (28) is rich in cognitive effect, and since the process of its recovery at all stages has followed the path of least effort by utilising only those assumptions rendered most immediately available in the communicative context, (28) may be viewed as an (implicitly communicated) optimally relevant hypothesis about the informative intention of the originator, i.e. as the relevant interpretation of (1). Given the kind of situational assumptions about instructional discourse that were outlined in section 6 , the receiver now has ample evidence to subsequently construe (1) in speechact terms as a specification of the assumption schema (6), i.e. as an instruction.

Note that the interpretation process is non-demonstrative insofar as it cannot be guaranteed that (28) construes the informative intention of the originator. However, to the extent that the premises employed in the demonstrative process of deduction are true, (28) will indeed be a true representation of the informative intention. This actually accounts for the seeming probabilistic or inductive nature of implicatures, which are generally taken to be loose in the sense of being cancellable, or defeasible (cf. Grice 1975). While Levinson (1983: 114), as Blakemore (1992: 14) has noted, points to the logical truth that the addition of new premises to already existing sets cannot cancel deductively inferred conclusions (which counters the defeasibility claim, ostensibly in favour of an inductive view of inference), his observation overlooks the fact that different sets of premises will deductively determine different conclusions (ibid.). In this way, the situational assumptions supplied by the generic frame are inferentially significant: in any other non-instructional context, the utterance will be interpreted according to a quite different set of assumptions.

\section{Final remarks}

Above I have tried to identify, at a very general level, some of what I have been calling the situational properties of technical instructional discourse, and I have attempted to outline within the general framework of relevance theory how representations relating to those properties and specified by an instructional generic frame might conceivably contribute to the interpretation of utterances such as (1). A principled inferential model of interpretation which takes underdetermined semantic representations and generic assumptions about the discourse as input and yields 
132

mental representations pairing desirable states-of-affairs with potential but as yet unrealised situations involving the receiver as agent clearly has some considerable descriptive and explanatory potential with regard to accounting for how utterances like (1) - (5) are actually understood. Indeed, the basic descriptive apparatus as outlined here would seem to provide a powerful analytical tool for the wider investigation of the complex relationships between language system, special discourse context and meaning representation.

During the course of this article I have pointed to a couple of areas of potential conflict between a relevance-based approach and other frameworks more traditionally employed in illuminating matters of genre. I suggested that relevance theory with its reliance on pragmatic inference was intrinsically better equipped than a code-based semiotic theory to deal with the complex issue of how linguistic signals are cognitively transformed into functional meaning representations. Similarly, I noted that a non-cognitive semiotic theory of genre relying on notions of intention and purpose by its very nature would seem to be considerably disadvantaged compared to a relevance-based cognitive approach. I also referred to Sperber \& Wilson (1997), who have addressed claims as to the ostensibly 'asocial' nature of relevance theory, and I pointed in that respect to how the framework actually would seem to provide principled access to the role of sociocultural phenomena in the process of linguistic interpretation in instructional discourse. More specific treatment of such issues, however, lies firmly outside the scope of the present paper.

\section{References}

Aitken, M. (2000). Directives and Indirectness: The Semantics and Pragmatics of Instructional Discourse. PhD thesis. Copenhagen Working Papers in LSP 8-1999/ 2000, Copenhagen Business School.

Askehave, I. \& J. M. Swales (2001). Genre identification and communicative purpose: a problem and a possible solution. In Applied Linguistics 22/2. 195-212.

Bache, C. \& N. Davidsen-Nielsen (1997). Mastering English Grammar: An Advanced Grammar for Non-native and Native Speakers. Berlin and New York: Mouton de Gruyter.

Bhatia, V. K. (1993). Analysing Genre: Language Use in Professional Settings. London: Longman.

Blakemore, D. (1992). Understanding Utterances: An Introduction to Pragmatics. Oxford: Blackwell. 
Butler, C. S. (1987). Communicative function and semantics. In M. A. K. Halliday \& R. P. Fawcett (eds) New Developments in Systemic Linguistics Vol. 1: Theory and Description. London and New York: Frances Pinter. 212-229.

Butler, C. S. (1988). Systemic linguistics, semantics and pragmatics. In E. H. Steiner \& R. Veltman (eds) Pragmatics, Discourse and Text: Some Systemically-inspired Approaches. Norwood, NJ: Ablex Publishing Corporation. 13-27.

Carston, R. (1988). Implicature, explicature and truth-theoretic semantics, reprinted in S. Davis (ed.) (1991) Pragmatics. A Reader. Oxford: Oxford University Press, 3352.

Durst-Andersen, P. (1992). Mental Grammar: Russian Aspect and Related Issues. Columbus, Ohio: Slavica Publishers, Inc.

Grice, H. P. (1975). Logic and conversation, reprinted in S. Davis (ed.) (1991) Pragmatics. A Reader. Oxford: Oxford University Press, 305-316.

Halliday, M. A. K. (1984). Language as code and language as behaviour: a systemicfunctional interpretation of the nature and ontogenesis of dialogue. In R. P. Fawcett, M. A. K. Halliday, S. M. Lamb \& A. Makkai (eds) The Semiotics of Culture and Language Vol. 1: Language as Social Semiotic. London and New York: Frances Pinter. 13-27.

Halliday, M. A. K. (1994). An Introduction to Functional Grammar (Second edition). London: Edward Arnold.

Klinge, A. (1993). The English modal auxiliaries: from lexical semantics to utterance interpretation. In Journal of Linguistics 29. 315-357.

Levinson, S. (1983). Pragmatics. Cambridge: Cambridge University Press.

Lyons, J. (1977). Semantics. Cambridge: Cambridge University Press.

Martin, J. R. (1992). English Text: System and Structure. Amsterdam: John Benjamins.

Perkins, M. (1983). Modal Expressions in English. London: Frances Pinter.

Searle, J. R. (1975). Indirect speech acts, reprinted in J. R. Searle (1979) Expression and Meaning: Studies in the Theory of Speech Acts. Cambridge: Cambridge University Press, 30-58.

Sperber, D. (1996). Explaining Culture: A Naturalistic Approach. Oxford: Blackwell.

Sperber, D. \& D. Wilson (1986/1995). Relevance: Communication and Cognition. Oxford: Blackwell.

Sperber, D. \& D. Wilson (1987). Précis of Relevance: Communication and Cognition. In Behavioural and Brain Sciences 10. 697-754.

Sperber, D. \& D. Wilson (1997). Remarks on relevance theory and the social sciences. In Multilingua 16. 145-51.

Swales, J. M. (1990). Genre Analysis: English in Academic and Research Settings. Cambridge: Cambridge University Press. 
134

Talbot, M. (1994). Relevance. In R. Asher (ed.) The Encyclopedia of Language and Linguistics 8. 3524-7.

Thibault, P. J. (1999). Communicating and interpreting relevance through discourse negotiation: An alternative to relevance theory - A reply to Franken. In Journal of Pragmatics 31. 557-594.

Unger, C. (2001). On the Cognitive Role of Genre: A Relevance-theoretic Perspective. $\mathrm{PhD}$ thesis. University of London.

Ward, G. \& L. Horn (1999). Phatic communication and relevance theory: A reply to Zegarac \& Clark. In Journal of Linguistics 35. 555-564.

Wilson, D. (1998). Discourse, coherence and relevance: A reply to Rachel Giora. In Journal of Pragmatics 29. 57-74. 